\title{
Study on the Coordinated Development of Rural Revitalization and New Urbanization in Dazhou City
}

\begin{abstract}
Xiaomei Pu
Research Center of Sichuan Old Revolutionary Areas Development, Sichuan University of Arts and Science, Dazhou, China Email: 47872614@qq.com
\end{abstract}

How to cite this paper: Pu, X.M. (2019) Study on the Coordinated Development of Rural Revitalization and New Urbanization in Dazhou City. Voice of the Publisher, 5 , 62-75.

https://doi.org/10.4236/vp.2019.53005

Received: September 8, 2019

Accepted: September 27, 2019

Published: September 30, 2019

Copyright ( 2019 by author(s) and Scientific Research Publishing Inc. This work is licensed under the Creative Commons Attribution International License (CC BY 4.0).

http://creativecommons.org/licenses/by/4.0/

\begin{abstract}
Rural revitalization and new urbanization are inevitable to build socialist modernization and realize regional coordinated development. Both of them are indispensable and cannot be neglected. Therefore, in order to promote the coordinated development of rural revitalization and new urbanization, these four aspects are needed. First, unified planning should be taken to promote the rational flow of urban and rural factors. Second, deepen the reform of rural land system to lay the foundation for the coordinated development of rural renewal and new urbanization. Third, raise funds through multiple channels to provide guarantee for it. Fourthly, we should train and introduce talents in various ways to provide support.
\end{abstract}

\section{Keywords}

Dazhou City, New Urbanization, Rural Revitalization,

Coordinated Development

\section{Introduction}

Rural revitalization and new urbanization play an important role in build socialist modernization and realize regional coordinated development, which is necessary and inevitable.

Dazhou, as an old revolutionary area and poverty-stricken city, the terrain is mainly mountainous and hilly. Hence, the task of revitalizing the countryside is even more arduous, and the road of new urbanization is tougher. It is also necessary to strengthen research on rural revitalization and new urbanization. 


\section{Current Situation and Problems of Rural Revitalization in Dazhou City}

There are many problems in Dazhou, such as large rural area and population, inadequate rural agricultural development and so on. It is significant for our city to build the provincial economic sub-center and the regional central city of the Sichuan-Bangshan-Shaanxi junction through implementing the strategy of rural revitalization and accelerating the priority development of rural agriculture.

The 19th National Congress of the Communist Party of China put forward the general requirements for rural revitalization: "Industrial prosperity, ecological livability, rural civilization, effective governance, and prosperous life". This study also researches the development and problems of rural revitalization in Dazhou from these major aspects.

\subsection{Industrial Prosperity}

Industrial prosperity is one of the key tasks of Dazhou Rural Revitalization Strategic Planning During 2018-2022, which includes the construction of high-quality granaries, upgrading the scale of agriculture, strengthening the construction of quality brands, promoting the "fly" action of agricultural science and technology, integrating rural industries and promoting agricultural open cooperation.

Dazhou is a large agricultural city. In 2017, the added value of the primary industry was 32.213 billion yuan, accounting for $20.3 \%$ of the GDP of Dazhou, which is higher than the average level of Sichuan 8.7 percentage points, and 12.4 percentage points than the national average. In order to speed up the transformation of Dazhou City from the big agricultural city to the strong agricultural city, government adheres to the structural reform of the agricultural supply side as the main line, and insists on using poverty alleviation to tackle the problems of agriculture, countryside and farmers and the overall situation of county development. And vigorously implement five major projects, including rural infrastructure construction, agricultural industrialization development, construction of a happy and beautiful new village, continuous poverty reduction, and agricultural and rural system reform, to accelerate the transformation of agricultural development. These measures have made the agricultural and rural economy show a good momentum of healthy and rapid development.

In 2017, grain sowing area was 569,900 hectares, an increase of $0.6 \%$ over the previous year. Among them, 177,000 hectares of rice increased by $0.6 \%, 1,035,000$ hectares of corn by $0.6 \%, 163,900$ hectares of potatoes by $2.5 \%, 137,700$ hectares of oil by $1.1 \%$ and 94,100 hectares of vegetable by $0.9 \%$. The annual grain output was 2.9606 million tons, an increase of 35.4 million tons over the previous year with an increase of $1.2 \%$, and the oil output was 340.1 million tons with an increase of $2.1 \%$.

The level of agricultural scale has been continuously improved, and these kinds of demonstration zones have been established: 30 national and provincial 
modern agricultural demonstration zones and 10,000 mu billion yuan of demonstration zones, 2 provincial agricultural integration demonstration zones, and 9 municipal modern agricultural integration demonstration zones. There has 2.2 million mu planting area of "Yipaisanhua" base, and the meat output is 500,000 tons.

Brand influence is rising rapidly. We have successfully created 4 well-known trademarks in China, 50 national geographical indications protection products, 21 national ecological origin protection products (Ranked the first in Sichuan Province), 36 famous brand products, 30 famous trademarks, 21 green products, 15 organic products and 178 pollution-free products. A number of agricultural products renowned internationally: JiuyuanBlack Chicken, Bashan Sparrow Tongue Tea, Translucent Beef Slices, Dazhu Fermented Glutinous Rice Wine and so on.

Agricultural science and technology are booming, especially in cold chain of agricultural products, logistics and e-commerce, which commodity rate reaching $60 \%$. RuralTaobao, Internet Plus, and E-commerce platform have been gradually distributed in rural areas. Wanyuan city, Qu county, Xuanhan county, and Tongchuan district have been identified as state-level rural e-commerce demonstration areas. The business platforms such as Vegetable Basketand Urban and Rural Communication have been put into operation, and online shopping network sales have reached 2 billion yuan.

The development of rural industrial integration showed a rapid momentum. A number of modern agricultural finca, agricultural theme park, agricultural characteristic town and agricultural science park have been built up, such as the Yang Lie water village in Xuanhan city, Kaijiang Pagoda and Lotus, Bi Yao manor in $\mathrm{Qu}$ county, and Miyan Flowers. It has promoted the integrated development of industries, and realized the transformation of parks into scenic spots, rural areas into parks, products into commodities, farming into exercise and deserted town into popularity.

New progress has been made in agricultural open cooperation. The import and export trade of agricultural products has increased rapidly, and exports have exceeded 100 million US dollars. Among them, Huae green food has been signed orders annually with European Union about 11 million euros. Some products like Dongliu rice wine and Yuzhu Ramie industry have been exported to the United States, Russia, the European Union, Japan and other countries.

But at the same time, we should focus on the landform and physiognomy, which lead to the high development costs, and hard to develop. These disadvantages should be considered. First, the low level of agricultural mechanization, it is estimated that the average agricultural machinery power in Dazhoucity was 4.9 kilowatts per hectare in 2017, which was $1.7 \mathrm{~kW} /$ ha lower than the average level of Sichuan. Second, the development system of modern agriculture is not perfect enough, and without large scale. In 2017, the proportion of protected agricultural land in cultivated land was less than 3\% in Dazhou. 
Thirdly, without enough technology support, there are lacking of brand building, the long agricultural chain, the supply of high-quality agricultural products, the competitiveness, and the productivity of agricultural labor force. In 2017, the agricultural labor productivity in Dazhou city was 19,744 yuan per person, which is 4029 yuan lower than the average level of Sichuan province. Fourthly, the rural industrial structure is single. The development degree of integration of primary, secondary and tertiary industries need to be improved, and the new agricultural format and new economy are still in the initial stage.

\subsection{Ecological Livability}

The ecologically livable countryside is one with perfect infrastructure, clean and tidy village appearance, stable natural ecosystem, which has blue sky, green land and clear water.

In recent years, Dazhou city has vigorously implemented the three major projects, such as Rural Road Interchange Project, irrigation and water conservancy energy recovery project and energy communication village and village project, which has greatly improved the level of rural infrastructure. Starting from the construction of beautiful towns and villages, aiming at improving the quality of rural environment, we should pay close attention to the Three Promotion and Three Developing, and further implement the Five Governance project into rural areas and communities to constantly improve rural human settlements and developing environment. According to the Special Monitoring Report on Rural Environmental Quality in Dazhou City in 2018 which released by the Dazhou Environmental Protection Burea, the air quality of villages in Wanyuan city is excellent, with $100 \%$ of the days reaching the standard, and the water quality of drinking water sources is classified as Class II (high quality of water).

But Dazhou is still facing many problems in building the ecologically livable rural areas. First, the problem of rural infrastructure is still prominent. There are many narrow roads in the countryside, and the roads are seriously damaged. Secondly, environmental and ecological problems are still severe. Agricultural resources and environment are under great pressure, and water source pollution is still serious. By the end of 2018, the centralized sewage treatment facilities in 304 rural townships had been built and put into, but the usage is only $20 \%$. While 152 township domestic garbage has not been treated harmlessly.

At the same time, the built sewage treatment plant has insufficient treatment capacity. The system of household collection, village collection, town transport, county treatment is difficult and costly, and the centralized collection, transportation and disposal system is not perfect. In 2017, the chemical fertilizer application amount was 218.9 thousand tons, accounting for $9 \%$ of the total chemical fertilizer application in the whole province, and the application amount per hectare was 0.397 tons, which was $10 \%$ higher than that of the average, resulting in serious pollution of land and water. According to the Special Monitoring Report on Rural Environmental Quality in Dazhou City in 2018 which released by the 
Dazhou Environmental Protection Burea, the air quality of villages in Xuanhan city is good, and the water quality of drinking water sources is classified as Class III (good quality of water).

\subsection{Rural Civilization}

Rural civilization construction is the soul of rural revitalization. Rural civilization is the countryside with civilized rural style, good family style, simple folk style and excellent culture.

Taking the civilized villages and towns, the outstanding villages and the civilized families as the starting point, Dazhou city vigorously promotes the construction of the socialist core values, the inheritance of farming culture, the family training and family training, and the construction of traditional filial piety culture. At present, the city has successfully established 10 national civilized villages, 23 provincial civilized villages, 285 municipal civilized villages, 100 provincial outstanding villages, 480 municipal outstanding villages, 6 provincial civilized families, and 97 municipal civilized families. Through the construction of the series of the new rural cultural platforms, like art exhibition, artistic exchange, talents incubation, tourism integration and so on, it has vigorously promoted the development of the rural cultural industry, and form many rural cultural tourism demonstration bases integrating performance, exhibition, exhibition, marketing and tourism, such as Yanglienew village in Xuanhan city, Changle new village in Dazhu city, Kaijiang Pagoda village.

However, there are still unhealthy customs and stereotypes in rural areas. There is still lack of cultural facilities such as farmhouse bookstores, cultural activities rooms, farmers' fitness sports venues and so on. The rural cultural industry is still in its infancy, and the traditional history and culture need to be further explored.

\subsection{Effective Governance}

Effective rural governance is the cornerstone of effective national governance. Effective rural governance is a combination of rule of law, virtue and autonomy. It is a modern, vibrant, stable and orderly rural with Party committee leadership, government responsibility, social coordination, public participation and guarantee of the rule of law.

The city has vigorously promoted the standardization of Party branches in rural areas, and the basic unit party building in rural areas has been markedly strengthened. Comprehensively implement the system of democratic decision-making, democratic management and democratic supervision on major village-level matters, and implement the system of Four discussions and Two openness, financial openness, and list of minor powers for village cadres, so as to guarantee villagers' right to participate in management. Rural rule of law construction has been strengthened in an all-round way through the Supervision Project $h$ and the Demonstration Village of Democracy and Rule of Law Activity which consolidate the stable and harmonious situation in rural areas. 
However, at present, there are still a few peasants in Dazhou rural areas who lack the sense of collective cooperation, awareness of law and discipline, social ethics and so on. Some rural basic unit organizations are scattered, and the ability and system of rural governance need to be strengthened.

\subsection{Prosperous Life}

Richness of life is the foundation to promote farmers' all-round development, and the inevitable requirement of realizing common prosperity. The well-off countryside is a countryside where the peasants have a steady income source, a well-off economy, sufficient food and clothing, well developed housing, transportation, medicine and education.

In recent years, living standard of farmers in Dazhou has been improving by vigorously developing characteristic industries, rural tourism, deepening the reform of the rural property rights system, strengthening labor export and implementing the policy of benefiting farmers. The disposable income of farmers in the whole city increased from 7047 yuan in 2012 to 12,843 yuan in 2017, an increase of $82 \%$. The coefficient of rural residents decreased from $52 \%$ in 2012 to $42 \%$ in 2017 . Overcoming poverty has achieved phased results. The number of poor people in rural areas has decreased from 716,000 in 2014 to 190,800 by the end of 2017. The incidence of poverty has dropped from $9.16 \%$ at the end of 2015 to $3.67 \%$ at the end of 2017 , down by 5.49 percentage points. The basic public services such as compulsory education, medical care and social security in rural areas have been continuously improved.

Although the living standard of farmers in Dazhou has improved, the problems are still significant. First, there are two counties in the level of poverty: Xuanhan and Wanyuan. Second, there is still a big gap between the income level of the peasants and the whole country. In 2017, the per capita net income of the farmers in the rural areas was 589 yuan, which is lower than the national average level. Third, the proportion of food expenditure was still large. In 2017, the rural residents' coefficient was $21 \%$ higher than the average level, which was $11 \%$ higher than the national level.

\section{Current Situation and Problems of New Urbanization}

The new urbanization is the urbanization of people-oriented, synchronization of four modernizations, optimization of layout, ecological civilization and inheritance of culture [1]. The new urbanization involves a wide range. This study draws on the relevant literature [2] [3] [4] combined with the national policy [1] [5]-[10], mainly from the population urbanization, spatial urbanization, economic urbanization and other major aspects to measure the development and problems of the new urbanization.

\subsection{Population Urbanization}

Population urbanization refers to the process of changing rural population into 
urban population and agricultural population into non-agricultural population. It mainly includes the urbanization rate of household registration population, the urbanization rate of resident population, the proportion of employed population in secondary and tertiary industries, and the social security situation of urban population.

In recent years, the government of Dazhou city has further liberalized the settlement conditions of the central cities, counties and towns. It also further clarified the encouragement policy for the agricultural transfer population to settle in place nearby, and comprehensively implemented the residence permit system for floating population. Therefore, the urbanization rate of Dazhou has been steadily improved. In 2017, the urbanization rate of the registered population was $31.6 \%, 14.4$ percentage points higher than that in 2005 , and the rate of urbanization for the permanent population was $43.9 \%$, which was 18.4 percentage points higher than that in 2005. With the optimization and upgrading of the industrial structure of Dazhou, the absorption capacity of urban population to the agricultural population has been further increased. The proportion of the employed population in the secondary and tertiary industries has increased from $35.3 \%$ in 2005 to $50.6 \%$ in 2017 , an increase of 15.3 percentage points. At the same time, the government further optimized the employment and entrepreneurship policy and continued to promote the people's livelihood project, so that the per capita disposable income of urban residents in Dazhou increased steadily, from 6541 yuan in 2005 to 28,383 yuan in 2017 . The social security level has been greatly improved. The average number of hospital beds per 10,000 people increased from 16.8 in 2005 to 52.6 in 2017, and the average number of medical technicians per 10,000 people increased from 23.6 in 2005 to 43.6 in 2017. Furthermore, the ratio of teachers and students in basic education increased from 1:25.8 in 2005 to $1: 17.6$ in 2017.

Although the urbanization level of population in Dazhou has been steadily improved, it is still need to be improved. In 2017, compared with Sichuan province, in the urbanization rate of the registered population, it was lower than 2.6 percentage points; in the urbanization rate of the resident population, it was lower than 6.9 percentage points; in the proportion of the employed population of the secondary and tertiary industries, it was lower than 12.6 percentage points, in the disposable income of urban residents, it was lower than 2344 yuan; in the number of hospital beds per 10,000 people, it was lower than 15.3; in the average number of medical technicians per 10,000 people, it was lower than 20.4; and in the number of students enrolled in basic education teachers, it was lower than 1.2 .

\subsection{Spatial Urbanization}

Spatial urbanization refers to the transformation of rural areas into urban areas and the transformation of rural landscapes into urban landscapes. It mainly includes the proportion of the built-up area to the urban area, the green coverage rate of the built-up area, and the per capita urban road area. 
In recent years, the city has actively promoted the construction of new districts in the central city, the construction of new towns in counties, and the construction of pilot towns, so that the built-up area of the city has been increasing, which has increased by nearly 5 times from 2005 to 2017. Dazhou constantly improve the quality of urbanization, the construction of shantytowns, affordable housing, transportation and other people's livelihood projects. It also vigorously promote the construction of green cities, and a lot of parks have been successively built, such as Lianhua Lake, Tatuo Pagoda, Ludingzhai Park, Dazhaizi Park, Lishuping Park, etc. The green coverage rate of the built-up area increased from $17.7 \%$ in 2006 to $31.9 \%$ in 2017.

Due to Dazhou is mainly covered by mountainous and hills, it is difficult to develop, with high costs and the limited urbanization space. Compared with $\mathrm{Si}$ chuan province, the per capita urban road area was 2.25 square meters in 2017 , which was less than $1 / 6$ of the province's average level. While the green coverage rate of the built-up area was 8.1 percentage points lower than the provincial average.

\subsection{Economic Urbanization}

Economic urbanization refers to the process of centralized development of nonagricultural industries to cities and towns. Economic urbanization includes not only the concentration of industries in towns and their regions, but also the optimization and upgrading of industrial structure. Therefore, this study evaluates the development and problems of the economic urbanization of Dazhou from the aspects of the output value of the secondary and tertiary industries, the GDP density of the secondary and tertiary industries, the energy consumption per unit of GDP, the proportion of information transmission, and the ratio of software and information technology service personnel.

Under the concept of integrated development of production city, the government of Dazhou pays close attention to the construction of major projects, industrial transformation and upgrading, and guarantees of production factors, so that the economic urbanization of Dazhou has been steadily improved. In 2017, the proportion of output value of secondary and tertiary industries was $79.7 \%$, an increase of 13.8 percentage points over 2005. The GDP density of secondary and tertiary industries was 75,404 yuan in 2017, more than three times that of 2005. And the proportion of information transmission, software and information technology service personnel increased by 32\% during 2005 and 2017. While, the energy consumption per unit GDP in 2017 decreased by 132 tons of standard coal per million yuan when compare with 2005.

But in general, the level of Economic Urbanization in Dazhou is still relatively backward. Compared with the average level in Sichuan, in 2017, the proportion of output value of the secondary and tertiary industry in Dazhou was lower than 8.7 percentage points, the GDP value of the secondary and tertiary industry was lower than 30,853 yuan, the proportion of software and information technology 
service personnel was less than $85 \%$, and the gross domestic product of the unit was higher than 0.155 tons of standard coal per 10,000 yuan.

\section{The Necessity and Feasibility Analysis of the Coordinated Development of Rural Revitalization and New Urbanization of Dazhou City}

From the above research and analysis, we can see that great achievements of rural revitalization and new urbanization in Dazhou have been made in recent years. But there are still have a lot of problems, and these problems can hardly be solved if only focus on themselves. New urbanization and Rural Revitalization are both important ways to realize modernization and solve the problems in agriculture, rural areas and farmers. They are closely linked with each other and promote each other. Since the strategy of rural revitalization put forward in the Nineteenth National Congress of the Communist Party of China, experts and scholars have fully demonstrated theoretically the necessity of synchronous promotion and coordinated development of Rural Revitalization and new urbanization, such as Caifang [2], Caijiming [11], Zhuomacao [12]. Chenguosheng, Dingcuicui and GuoQingran [13] have made an empirical study on the relationship between new urbanization and rural revitalization by using 1994-2016 data, and the result shows that there is a positive impact between them.

Rural revitalization and new urbanization are consistent in purpose, task, principle, leadership, development mode and system supply. From the point of view of purpose, the new urbanization is the urbanization with human as the core, and its ultimate goal is to benefit the people. The general requirement of rural revitalization is to achieve thriving industry, livable ecology, civilized rural style, effective governance and affluent life, and the ultimate goal is to make farmers have a better life. In the point of task, the most important thing of urbanization is to promote the transfer of population from agriculture to urbanization, and it is also one of the main tasks of rural revitalization at this stage. In principle, the new urbanization is to promote urbanization and coordinate the construction of new countryside. The rural revitalization strategy also clearly proposes to adhere to the development of urban and rural integration, and accelerate the formation of a new type of urban-rural relations between workers and farmers, with mutual promotion, mutual complementation, comprehensive integration, and common prosperity. From the perspective of leadership, urbanization and rural revitalization were written in the reports of the 18th and 19th National Congresses respectively, which should be promoted under the leadership of the Party. From the perspective of development mode, the green development highlighted by the new urbanization is the same as the ecological livability emphasized by rural revitalization. From the perspective of system supply, new urbanization and rural revitalization need effective land system, household registration system, and fund-raising system, through unified deployment and arrangement [14].

It is necessary to implement the rural revitalization and the coordinated development of new urbanization. First, it can provide employment posts for rural 
surplus labor force to promote the production and sale of agricultural products, and then promote the prosperity of rural industry and prosperity of life. It will also promote the extension of infrastructure, public services, resource elements, ecological concepts to rural areas, finally effectively promote rural ecological livability, rural civilization, effective governance, and realize rural revitalization. Second, it contribute to capital and talent going to the countryside, promote the return of migrant workers to cities and local urbanization, solve the problems of traffic congestion and rising housing prices in urban areas, and accelerate the high-quality development of urbanization. Third, it is conducive to promote the development between urban and rural in the rational division and cooperation of industries, the equalization of public services between urban and rural areas, narrowing the income gap between urban and rural areas, and realizing the integration of urban and rural development. As general secretary Xi pointed out that urbanization should be developed, agricultural modernization and new rural construction also should be developed, and simultaneous development can complement each other.

\section{Countermeasures for the Coordinated Development of Rural Revitalization and New Urbanization in Dazhou City}

Both rural revitalization and new urbanization are necessary to build socialist modernization. Only with the coordinated development of them, can we promote the integration of urban and rural development. To promote the coordinated development of Rural Revitalization and new urbanization, the following points should be done.

\subsection{Unified Planning to Promote Rational Flow of Urban and Rural Elements}

To promote the coordinated development of rural revitalization and new-type urbanization, we must first promote the rational flow of urban and rural factors, adhere to the integrated planning of urban and rural areas, coordinate the development of urban and rural land space, optimize the ecological layout of production and living, promote rural development in an orderly manner, and build a coordinated and integrated development pattern between urban and rural areas. Then, adhere to the rural driven by cities and rural service cities, break division of urban and rural in infrastructure, public service facilities and industrial layout planning, promote the integration of primary secondary and tertiary industries in urban and rural, gradually realize the rational allocation of urban and rural factors, and promote labor, land, technology, capital and other factors flow reasonably between urban and rural areas.

\subsection{Deepening the Reform of Rural Land System to Lay the Foundation}

Land is the core element of the development of modern agriculture and new urbanization. It is also the part of farmers' production and life and the core asset of 
income and wealth. First, land usage management should be strictly implemented and protect cultivated land. Support the development of facility agriculture, if permanent basic farmland and high-quality farmland did not been occupied. For the development of rural tourism, leisure, pension, health and other special industries, the implementation of point land supply is allowed. Protect as much as possible the land used for renovation of dangerous old houses in rural areas and for poverty alleviation and relocation. Secondly, it should implement the policy of stabilizing the contractual relationship of rural land for a long time and guarantee the farmers' operating income earnestly. It is necessary to establish the mechanism of paid transfer and withdrawal of rural contracted land and residential land, explore the mechanism of entering the market of rural collective operating construction land, increase farmers' property income, realize the scale management of farmers' land, and create conditions for agricultural modernization. Third, we should strengthen village renovation, homestead and rural idle construction land consolidation. People-oriented and local conditions should be adjusted to implement the project of linking the increase and decrease of urban and rural construction land, ultimately changing the living environment of farmers and increasing urban construction land. Fourthly, we should accelerate the reform of the rural land expropriation system, improve the compensation standards for land expropriation, establish a multi-security mechanism for the sustainable livelihood of land expropriated farmers, and effectively safeguard the interests of land expropriated farmers. Establish and improve the service system of land transfer, basically establish a service network covering county, township and village levels of rural land transfer, to ensure the healthy and orderly transfer of land.

\subsection{Multi-Channel Fund-Raising to Provide Guarantee}

Lack of funds is the biggest bottleneck in the revitalization of rural areas and the construction of new urbanization. We must raise funds through various channels to solve the problem of funds. First, we should make good use of special funds for infrastructure projects, and strengthen infrastructure construction, especially transportation network construction, so as to link the city's public transport network with rural areas and give full play to the radiation leading role of the urban area's traffic network. Second, fully utilize the special funds for industrial development, rural revitalization and urbanization construction to further strengthen the construction of living infrastructure, such as housing, hydropower, gas, telephone, broadband network, medical treatment and entertainment. Improve the construction of productive infrastructure, such as farmland water conservancy projects, tourism, agricultural products processing, packaging, logistics, cold chain, warehousing and payment, to develop green environment, improve living conditions of residents, and enhance attraction for talents. Third, we should eliminate the obstacles that hinder industrial and commercial capital from going to the countryside, realize the two-way flow of resources between 
urban and rural areas, and increase investment in agricultural mechanization, intelligent and informationized facilities and equipment. Fourth, we should establish a diversified and sustainable financial guarantee mechanism, promote the reform of policy-based financial institutions, play a good role in Rural Revitalization and new urbanization, and increase the financial supply for Rural Revitalization and new urbanization.

\subsection{Training and Introducing Talents in Various Ways to Provide Support}

Talent is a key factor and prominent problem in rural revitalization and new urbanization, not only in Dazhou city. In 2007, the household registration population was 6.717 million, the resident population was only 5.69 million, and the transfer population was 1.27 million (most of them are exit to other places). To solve the problem of talent development in rural revitalization and new urbanization, we must introduce preferential policies to attract talented people. We should strengthen the innovation and introduction of high-level talents, such as the introduction of technical backbone and subject leaders. Coordinate personnel, staffing, finance, health, and other relevant departments, to study and formulate relevant policies to solve the problems of staffing and treatment of outstanding talents. We should establish village cadres' economic treatment guarantee system, political incentive system, care system and so on, so as to attract talented people, veterans and retired cadres to the Two Committees team. Preferential policies should be implemented to encourage migrant workers and businessmen to return home and start their own businesses, so as to promote rural development. Another is to strengthen the training of practical talents. It is necessary to strengthen the vocational education and training of practical talents, enhance their scientific and technological qualities, and gradually become the new force in the revitalization of villages and the construction of new towns. Gradually raise these talents' income, so that they can return and retain.

\section{Conclusion}

Rural revitalization and new urbanization are the necessary ways to build socialist modernization and the inevitable choice to achieve regional coordinated development. In recent years, great achievements have been made in the revitalization of rural areas and the construction of new urbanization in Dazhou City, but there are still many problems. The fundamental reason lies in the fact that rural revitalization and new urbanization are still inconsistent in the development. How to promote the coordinated development of rural revitalization and new urbanization becomes an urgent problem to be solved. Based on the investigation of the current situation and existing problems of the development of rural revitalization and new urbanization in Dazhou City, combined with the experience of relevant provinces and cities in China, this paper puts forward countermeasures and suggestions for the coordinated development of rural revitalization and new urbanization in Dazhou city. 


\section{Funding}

This study was supported by the project of Sichuan Provincial Key Research Base of Social Sciences, Sichuan County Economic Development Research Center, Sichuan Synergy Promotion of New Urbanization and Rural Revitalization Strategy (Project No. xy2019007), Beautiful countryside Construction and Development Research Center (Project No. CCRC04) and Dazhou Social Science Association.

\section{Conflicts of Interest}

The author declares no conflicts of interest regarding the publication of this paper.

\section{References}

[1] Guangming Website (2018) 2014 Government Work Report. http://topics.gmw.cn/2018-07/05/content_29686942.htm

[2] Cai, F. (2018) Promoting the Vitalization of Rural Areas and the New Urbanization. Discovery in Chinese Village, 4, 12-16.

[3] Liu, X. (2019) Coupling Research on New Urbanization and Beautiful Rural Construction in Henan Province. Agricultural Resources and Regionalization in China, 1, 74-78.

[4] Fu, Z.X., Pu, X.M. and Cheng, Z.B. (2014) Study on the Level of Urbanization in Sichuan from the Perspective of Economy, Space and Population. Journal of China West Normal University, Philosophy and Social Sciences Edition, 6, 85-89.

[5] Xinhua Website (2013) Central Conference on Urbanization. http://www.xinhuanet.com/fortune/2013qgczhgzhy/index.html

[6] Ministry of Education of the People's Republic of China (2017) The State Council of the Central Committee of the Communist Party of China Issued the National New Urbanization Plan (2014-2020).

http://www.moe.gov.cn/jyb_xwfb/xw_zt/moe_357/jyzt_2016nztzl/ztzl_xyncs/ztzl_x y_zcfg/201701/t20170117_295057.html

[7] Guangming Website (2017) To Win the Victory of Building a Well-off Society in an All-Round Way and Win the Great Victory of Socialism with Chinese Characteristics in the New Era-A Report at the Nineteenth National Congress of the Communist Party of China by Xi. http://politics.gmw.cn/2017-10/27/content_26628091.htm

[8] Xinhua Website (2018) An Important Speech by Xi and Li in the Central Economic Work Conference in Beijing. http://www.xinhuanet.com/politics/leaders/2018-12/21/c_1123887379.htm

[9] Chinese Government Network (2019) 2019 Government Work Report. http://www.gov.cn/zhuanti/2019qglh/2019lhzfgzbg/index.htm

[10] National Development an Reform Commission (2019) National Development and Reform Commission of the People's Republic of China. Notice of the National Development and Reform Commission on Printing and Distributing the Key Tasks of New Urbanization Construction in 2019. http://www.ndrc.gov.cn/zcfb/zcfbtz/201904/t20190408_932843.html

[11] Cai, J.M. (2018) Rural Revitalization Strategy in Synchronization with New Urbanization. People's Forum, Academic Frontier, 10, 76-79. 
[12] Zhuoma, C. (2019) The Theoretical Basis and Realization Path of the Integration Development of Rural Revitalization and New Urbanization in the New Era. Economist, 1, 104-112.

[13] Chen, G.S., Ding, C.C. and Guo, Q.R. (2018) Empirical Study on the Relationship between New Industrialization, New Urbanization and Rural Revitalization Level Based on Entropy Weighting Method. Hunan Social Sciences, 6, 114-124.

[14] China Net (2018) Simultaneously Promoting Rural Revitalization and New Urbanization Strategy. http://opinion.china.com.cn/opinion_87_179687.html 